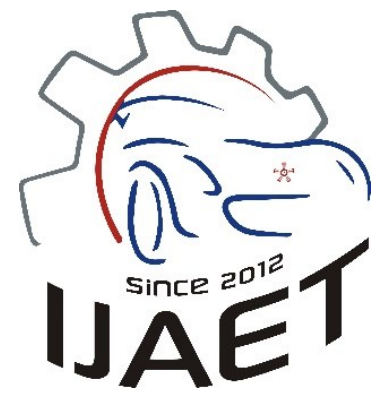

e-ISSN: 2146 - 9067

International Journal of Automotive

Engineering and Technologies

journal homepage:

https://dergipark.org.tr/en/pub/ijaet

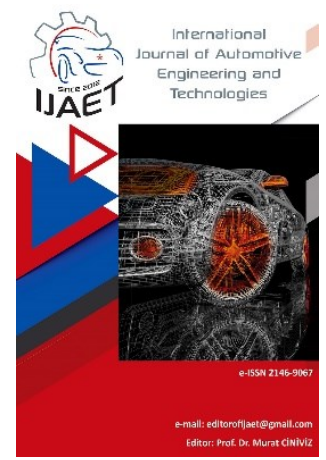

Original Research Article

\title{
Torque estimation of electric vehicle motor using adaptive- network based fuzzy inference systems
}

\begin{tabular}{|c|c|}
\hline${ }^{1 *}$ Electrical Electronics E & $\begin{array}{l}\text { Alper Kerem }{ }^{1 *} \\
\text { ing, Engineering And Architecture Faculty, Kahramanmaraş Sütçü İmam University, K.Maraş, } \\
\text { Turkey }\end{array}$ \\
\hline ARTICLE INFO & ABSTRACT \\
\hline 1. $0000-0002-9131-2274$ & $\begin{array}{l}\text { This paper presents to estimating studies of the torque data of the Electric Vehicle } \\
\text { (EV) motor using Adaptive-Network Based Fuzzy Inference Systems (ANFIS). }\end{array}$ \\
\hline Doi: $10.18245 /$ ijaet.879754 & The real-time data set of the Outer-Rotor Permanent Magnet Brushless DC \\
\hline $\begin{array}{l}\text { * Corresponding author } \\
\text { alperkerem@ksu.edu.tr }\end{array}$ & $\begin{array}{l}\text { (ORPMBLDC) motor which was designed and manufactured for using in ultra- } \\
\text { light EV, was used in these estimation process. The current, the power and the }\end{array}$ \\
\hline Received: Feb 13, 2020 & $\begin{array}{l}\text { motor speed parameters are defined as input variables, and the torque parameter } \\
\text { defined as output variable. Five distinct ANFIS models were designed for torque }\end{array}$ \\
\hline Accepted: Feb 17, 2021 & estimation process and the performances of each model were compared. The most \\
\hline Published: Mar 31, 2021 & $\begin{array}{l}\text { effective model for testing data set among the ANFIS models was anfis: } 2 \text { with } 98 \\
\text { nodes and } 36 \text { fuzzy rules, and the worst model was anfis: } 5 \text { with } 286 \text { nodes and }\end{array}$ \\
\hline $\begin{array}{l}\text { Published by Editorial Board } \\
\text { Members of IJAET }\end{array}$ & $\begin{array}{l}125 \text { fuzzy rules. Performance results of all designed models were presented in } \\
\text { tables and graphs. }\end{array}$ \\
\hline $\begin{array}{l}\text { (c) This article is distributed by } \\
\text { Turk Journal Park System under } \\
\text { the CC } 4.0 \text { terms and conditions. }\end{array}$ & $\begin{array}{l}\text { Keywords: Electric vehicle motor, Adaptive-Network Based Fuzzy Inference Systems (ANFIS), } \\
\text { Outer-Rotor Permanent Magnet Brushless DC (ORPMBLDC), torque estimation }\end{array}$ \\
\hline
\end{tabular}

\section{Introduction}

The global population and the number of cars in traffic are growing day by day. Fossil fuels used in Internal Combustion Engine (ICE) vehicles are in a state of exhaustion over time, and the gases emitted from these vehicles damage the ecosystem. On the other hand, Electric Vehicles (EVs) do not emit any greenhouse gases and are a good alternative to eliminating reliance on sources dependent on fossil fuels [1].

The widespread usage of EVs is related to the technical/ economic benefits of these vehicles will offer compared to ICE vehicles. These benefits may include less pollution, reduced consumption, reduced costs of management, lack of circulation constraints and reduced noise level. The main challenges of EV spread include insufficient number of charging stations, long standby time for charging [2] and battery range [3].

EV technology consist of battery, electric motor, motor driver circuit and transmission gears [4, 5]. Features like wide spread range, high power density, high efficiency and maintenance-free are expected from electric motors, which have an significant role in this technology [4].

In this study, real-time data such as current, power and motor speed of the Outer-Rotor Permanent Magnet Brushless DC (ORPMBLDC) motor, which was designed to be used in EV of Kahramanmaraş Sütçü İmam University named Kurtuluş, were modeled with 
Table 1. Some literature on estimation studies using ANFIS models

\begin{tabular}{|c|c|c|c|}
\hline Model & Implementation Area & Evaluation Metrics & Reference \\
\hline ANFIS & $\begin{array}{l}\text { Estimating the effect on emissions and motor performance of } \\
\text { the various proportions of methanol mixtures }\end{array}$ & RMSE, R & {$[6]$} \\
\hline ANFIS & Estimating the piles' bearing capacity & $\begin{array}{l}\text { RMSE, R, MAPE, } \\
\text { BIAS, SI }\end{array}$ & {$[7]$} \\
\hline ANFIS & Estimating the yields of biogas produced by combining waste. & $\begin{array}{l}\text { RMSE, R, R }{ }^{2}, \\
\text { MAE, SEP, AAD }\end{array}$ & [8] \\
\hline ANFIS & Estimating the crop yield & MSE, MAE, SSE & [9] \\
\hline ANFIS & Estimating the wind speed & MAPE, $\mathrm{R}^{2}$ & {$[10]$} \\
\hline ANFIS & $\begin{array}{l}\text { Estimating the producing of biogas from spent mushroom } \\
\text { compost }\end{array}$ & RMSE, R, R ${ }^{2}$ & {$[11]$} \\
\hline ANFIS & Estimating the groundwater level & RMSE, R², EV & {$[12]$} \\
\hline ANFIS & Inflation prediction & RMSE & {$[13]$} \\
\hline ANFIS & Shear capability prediction of channel shear connectors & MSE, $\mathrm{R}^{2}$ & {$[14]$} \\
\hline ANFIS & Estimating the content of sweet natural gas water & $\mathrm{R}^{2}$ & {$[15]$} \\
\hline ANFIS & Density estimating for bitumen-tetradecane mixtures & RMSE & [16] \\
\hline ANFIS & Heat capacity estimation of non-newtonian ionanofluid systems & $\begin{array}{l}\text { RMSE, R }{ }^{2} \text {, MSE, } \\
\text { MRE, STD }\end{array}$ & {$[17]$} \\
\hline ANFIS & Estimating the global solar radiation & RMSE, R ${ }^{2}$, MAE & {$[18]$} \\
\hline ANFIS & $\begin{array}{l}\text { Estimating the enthalpies of petroleum fractions and pure } \\
\text { hydrocarbons for vaporization }\end{array}$ & RMSE, $\mathrm{R}^{2}$ & [19] \\
\hline ANFIS & Estimating the charging status of the battery & MSE & {$[20]$} \\
\hline ANFIS & $\begin{array}{l}\text { Thermal conductivity enhancement estimation of } \\
\text { nanofluids depending on metal and metal oxide }\end{array}$ & $\begin{array}{l}\text { RMSE, MSE, R } \\
\text { AARD, STD }\end{array}$ & {$[21]$} \\
\hline ANFIS & $\begin{array}{l}\text { Estimating and optimizing the parameters affecting biodiesel } \\
\text { production yield and cost }\end{array}$ & RMSE, R, MAE & {$[22]$} \\
\hline ANFIS & $\begin{array}{l}\text { Predicting the compressive strength of cement-based mortar } \\
\text { materials }\end{array}$ & $\begin{array}{l}\text { RMSE, R², MAPE, } \\
\text { VAF }\end{array}$ & {$[23]$} \\
\hline ANFIS & $\begin{array}{l}\text { Prediction of ground vibrations arising from the blasting of } \\
\text { quarries }\end{array}$ & RMSE, R ${ }^{2}, \mathrm{VAF}$ & {$[24]$} \\
\hline ANFIS & Predicting the solar chimney power plants performance & RMSE, $\mathrm{R}^{2}, \mathrm{MAE}$ & {$[25]$} \\
\hline ANFIS & $\begin{array}{l}\text { Elastic modulus prediction of normal and high-strength } \\
\text { concrete }\end{array}$ & RMSE, MAPE & {$[26]$} \\
\hline ANFIS & Estimation of solar radiation & RMSE, R², MBE & {$[27]$} \\
\hline ANFIS & $\begin{array}{l}\text { Estimating the demand of biochemical oxygen of the Surma } \\
\text { River }\end{array}$ & $\begin{array}{l}\text { MSE, R, MAE, } \\
\text { EFF }\end{array}$ & {$[28]$} \\
\hline ANFIS & Wear a prediction of a multi-joint mechanism & NRMSE & [29] \\
\hline ANFIS & Wuhan City air quality prediction & $\begin{array}{l}\text { MSE, R }{ }^{2}, \quad M A E, \\
\text { MAPE }\end{array}$ & {$[30]$} \\
\hline ANFIS & $\begin{array}{l}\text { State estimation for load uncertainty and false data in electric } \\
\text { power systems }\end{array}$ & $\begin{array}{l}\text { RMSE, MAE, } \\
\text { MRE }\end{array}$ & {$[31]$} \\
\hline ANFIS & $\begin{array}{l}\text { Prediction of the concentration of } \mathrm{CO} \text { pollutants in the air in } \\
\text { Tabriz city }\end{array}$ & $\begin{array}{l}\text { RMSE, R }{ }^{2}, \mathrm{MAE}, \\
\mathrm{DC}\end{array}$ & {$[32]$} \\
\hline
\end{tabular}

Abbreviations:

AAD: Average Absolute Deviation, AARD: Average Absolute Relative Deviation, DC: Determination Coefficient, EFF: Model Efficiency, EV: Error Variation, MAE: Mean Absolute Error, MAPE: Mean Absolute Percentage Error, MBE: Mean Bias Error, MRE: Mean Relative Error, MSE: Mean Square Error, NS: NashSutcliffe coefficient, R: Correlation coefficient, $\mathrm{R}^{2}$ : Coefficient of determination, RMSE: Root Mean Square Error, NRMSE: Normalized Root Mean Square Error, P: Probability, SEP: Standard Error of Prediction, SSE: Sum Squared Error, STD: Standard Deviation, VAF: Variance Account For

ANFIS models and the torque data were estimated. Five distinct ANFIS models which are called anfis: 1 , anfis:2, anfis:3, anfis:4 and anfis: 5 were created and the successes of each model were observed. The estimation error values of the models were calculated with statistical metrics such as coefficient of determination $\left(\mathrm{R}^{2}\right)$, Mean Absolute Percentage Error (MAPE), Mean Square Error (MSE) and Root Mean Square Error (RMSE). Some literature on estimation studies using ANFIS models are given in Table 1. 


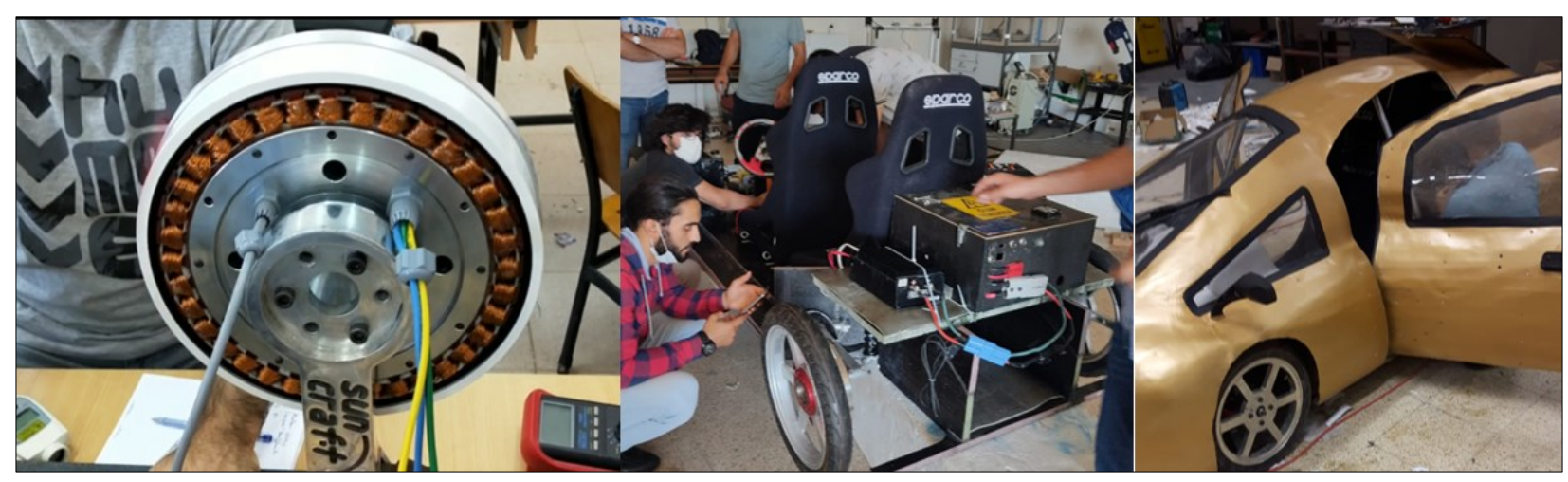

Figure 1. Implementation works of ORPMBLDC motor on ultra-light EV

Table 3. Statistical parameters of ORPMBLDC motor used in each ANFIS models

\begin{tabular}{lllllllll}
\hline & & \multicolumn{7}{c}{ statistical } \\
\cline { 3 - 9 } variable & category & $\min$ & average & $\max$ & std & median & variance & $\begin{array}{l}\text { total } \\
\text { data }\end{array}$ \\
\hline current & input & 1,290 & 12,125 & 23,350 & 7,624 & 11,445 & 57,925 & 300 \\
power & input & 48,620 & 1252,572 & 2092,060 & 720,514 & 1398,770 & 517410,203 & 300 \\
speed & input & 805,390 & 920,118 & 1027,150 & 80,455 & 951,090 & 6451,413 & 300 \\
torque & output & 0,420 & 12,482 & 22,550 & 7,823 & 12,770 & 60,999 & 300 \\
\hline
\end{tabular}

\section{ORPMBLDC Motor for EV}

BLDC motors are commonly used in the industry, particularly in the automotive sector. These motors have a simple structure, high speed range [33], high efficiency, simplistic control, compactness, quite low noise pollution [34], large initial torque with lower physical specifications, simplistic maintenance [35] and reduced weight thanks to absence of bruhes [36].

There are two types of BLDC motors: Permanent Magnet Brushless DC (PMBLDC) and Permanent Magnet Synchronous Motor (PMSM). These motors have distinct characters in terms of output wave back emf. Thus, the output wave back emfs are trapezoidal wave and sinusoidal wave for PMBLDC and PMSM, respectively [33].

\subsection{Experimental works}

In this study, the data of the ORPMBLDC motor, which was designed and prototyped to be used in ultra-light EV (driver and vehicle body $\sim 200 \mathrm{~kg}$ ), was used. Technical features of ORPMBLDC motor are given in Table 2.

Implementation works of ORPMBLDC motor on ultra-light EV are given in Fig. 1. Statistical parameters of ORPMBLDC motor used in each ANFIS models Table 3.

\section{ANFIS Structure}

A combination of Artificial Neural Network
(ANN) and Fuzzy Inference Systems (FIS) is considered to be the structure of the ANFIS model. In this model, a mapping between the inputs and outputs known as the "TakagiSugeno inference model" is produced according to "IF-THEN rules" [30]. It is a rule based system which has membership functions for input and output variables, fuzzy rules, and output characteristics and outcomes of the system [9].

Table 2. ORPMBLDC motor parameters (experimental)

\begin{tabular}{lcc}
\hline \multicolumn{1}{c}{ Parameters } & $\begin{array}{c}\text { Experimental } \\
\text { values }\end{array}$ & Unit \\
\hline slot / pole & $36 / 40$ & - \\
power & 2000 & $\mathrm{~W}$ \\
speed & 815,16 & $\mathrm{rpm}$ \\
torque & 21,4 & $\mathrm{Nm}$ \\
efficiency & $88,76 \%$ & - \\
voltage & 96 & $\mathrm{~V}$ \\
stator material & M330-50 A & - \\
& $\mathrm{AISI} / \mathrm{SAE}$ & \\
rotor material & $4340 \mathrm{Alloy}$ & - \\
& $\mathrm{Steel}$ & \\
magnet type & $\mathrm{N} 40 \mathrm{UH}$ & - \\
Weight (stator & $\sim 10,4$ & $\mathrm{~kg}$ \\
and rotor) & & \\
\hline
\end{tabular}

ANFIS model incorporates the Back Propagation (BP) and the Least-Square Model (LSM) as learning models, extracting structural properties such as the number of fuzzy rules, membership function coefficients, and the linear and nonlinear parameters numbers [7]. The general structure of ANFIS model is given in Fig. 2. 


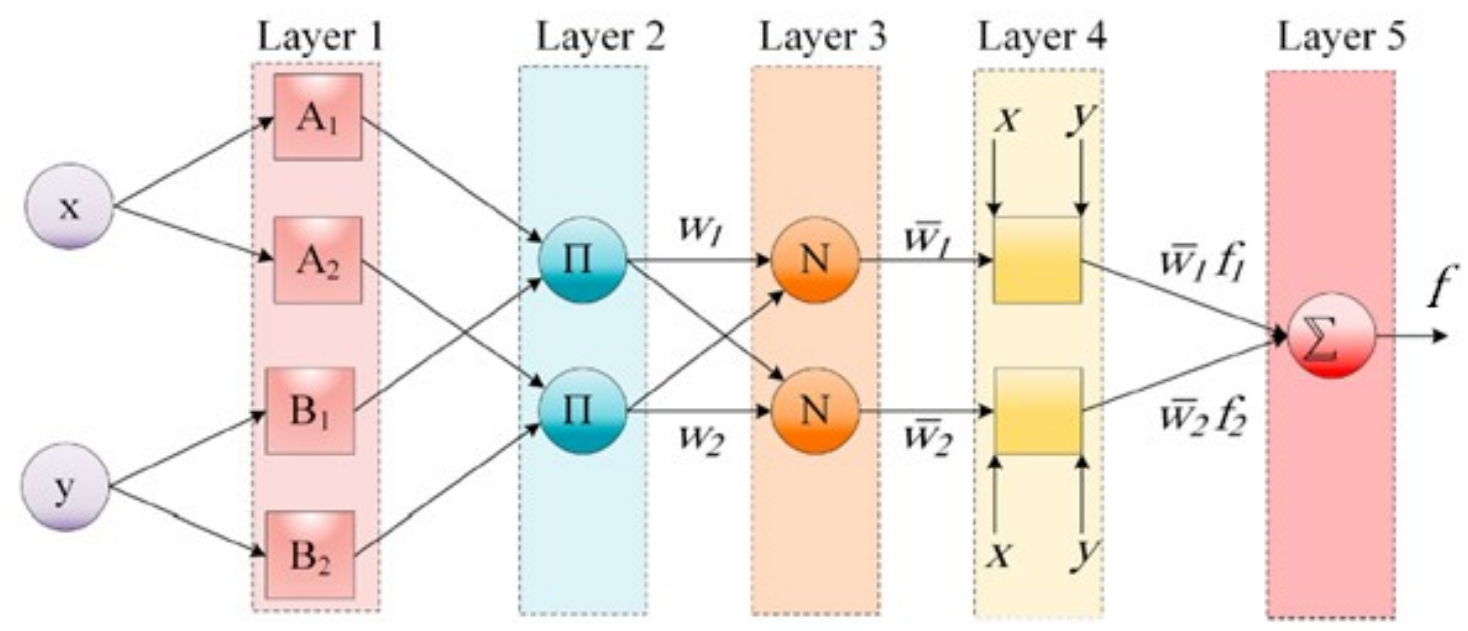

Figure 2. The general structure of ANFIS model [30]

Table 4. Layer parameters of ANFIS model

\begin{tabular}{|c|c|c|c|}
\hline parameter & definition & description & equ. \\
\hline Rule $i$ & $\begin{array}{c}\text { IF } x \text { is } A_{i} y \text { is } B_{i} \text { THEN } f_{i}=p_{i} x+q_{i} y+r_{i} \\
i=1,2, \ldots, n\end{array}$ & Rule $i$ & (1) \\
\hline$O_{i}^{1}$ & $O_{i}^{1}=\mu_{A i}(x), \quad O_{i}^{1}=\mu_{B i}(y)$ & first layer & (2) \\
\hline$O_{i}^{2}$ & $O_{i}^{2}=w_{i}=\mu_{A i}(x) \mu_{B i}(y)$ & second layer & (3) \\
\hline$O_{i}^{3}$ & $O_{i}^{3}=\sum w_{i}=\frac{w_{i}}{\sum_{i=1}^{n} w_{i}}$ & third layer & (4) \\
\hline$O_{i}^{4}$ & $O_{i}^{4}=\sum w_{i} f_{i}=\sum w_{i}\left(p_{i} x+q_{i} y+r_{i}\right)$ & fourth layer & (5) \\
\hline$O_{i}^{5}$ & $O_{i}^{5}=\sum_{i=1} \overline{w_{1}}, \quad f_{i} i=1,2, \ldots, n$ & fifth layer & (6) \\
\hline
\end{tabular}

ANFIS model has a five-layered feed forward network [12]. These layers are known as the layer of fuzzify, layer of product, layer of normalized, layer of defuzzifier, and layer of total output [14].

The first layer (Layer 1) is define as system fuzzification [7]. It obtains all input parameters and uses them to introduce to ANFIS [11]. The second layer (Layer 2) is the output of first layer. Calculation of firing strength is performed in this layer. Furthermore, each node multiplies input signals and gives out the product [7]. The third layer (Layer 3) normalizes the activity degree for whole rules [11]. The ratio is calculated for each weight and the total weight in this layer [14]. The fourth layer (Layer 4), each node outputs the crisp value of the corresponding fuzzy rule and, in addition, the output is computed between the output of the third layer and the linear combination of input variables by virtue of the product. The fifth layer (layer 5) contains just one node and, by summing all the outputs relevant to the fourth layer, provides the total crisp output value [7]. The layer parameters of ANFIS model are given in Table 4.

where $n$ is rules number, $p_{i}, q_{i}, r_{i}$ are the determined parameters on training process defined by Equ. (1). $\mu$ is Gaussian membership function, $A_{i}$ and $B_{i}$ linguistic labels defined by Equ. (2). $w_{i}$ is the ith the second layer's output defined by Equ. (3). $f$ denotes the function defined by Equ. (5) $[14,30]$.

\subsection{Design of ANFIS models}

In this study, the ANFIS models were developed using ANFIS toolbox on MATLAB software. The torque data was determined as an output variable, and, it is aimed to estimate to torque data by using input variables such as current, power and speed data. Input and output variables of designed ANFIS models are shown in Fig. 3.

Five distinct ANFIS models which are named 


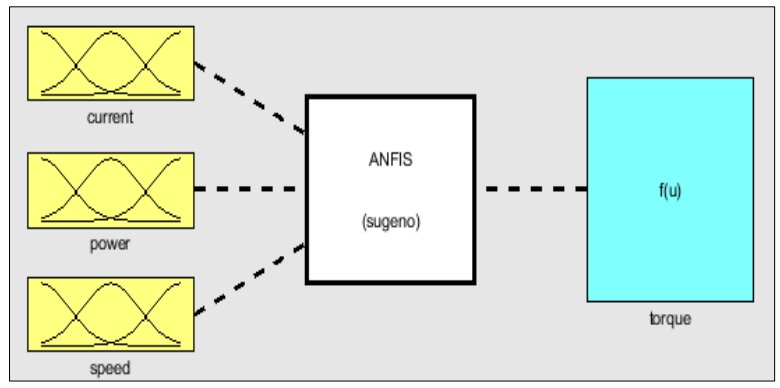

Figure 3. Input and output variables of designed ANFIS Models

Table 5. Specifications of designed ANFIS models

\begin{tabular}{lccccc}
\hline info & anfis:1 & anfis:2 & anfis:3 & anfis:4 & anfis:5 \\
\hline Number of nodes & 78 & 98 & 150 & 158 & 286 \\
Number of linear parameters & 27 & 36 & 60 & 64 & 125 \\
Number of nonlinear parameters & 27 & 30 & 36 & 36 & 45 \\
Total number of parameters & 54 & 66 & 96 & 100 & 170 \\
Number of training data pairs & 210 & 210 & 210 & 210 & 210 \\
Number of fuzzy rules & 27 & 36 & 60 & 64 & 125 \\
\hline
\end{tabular}

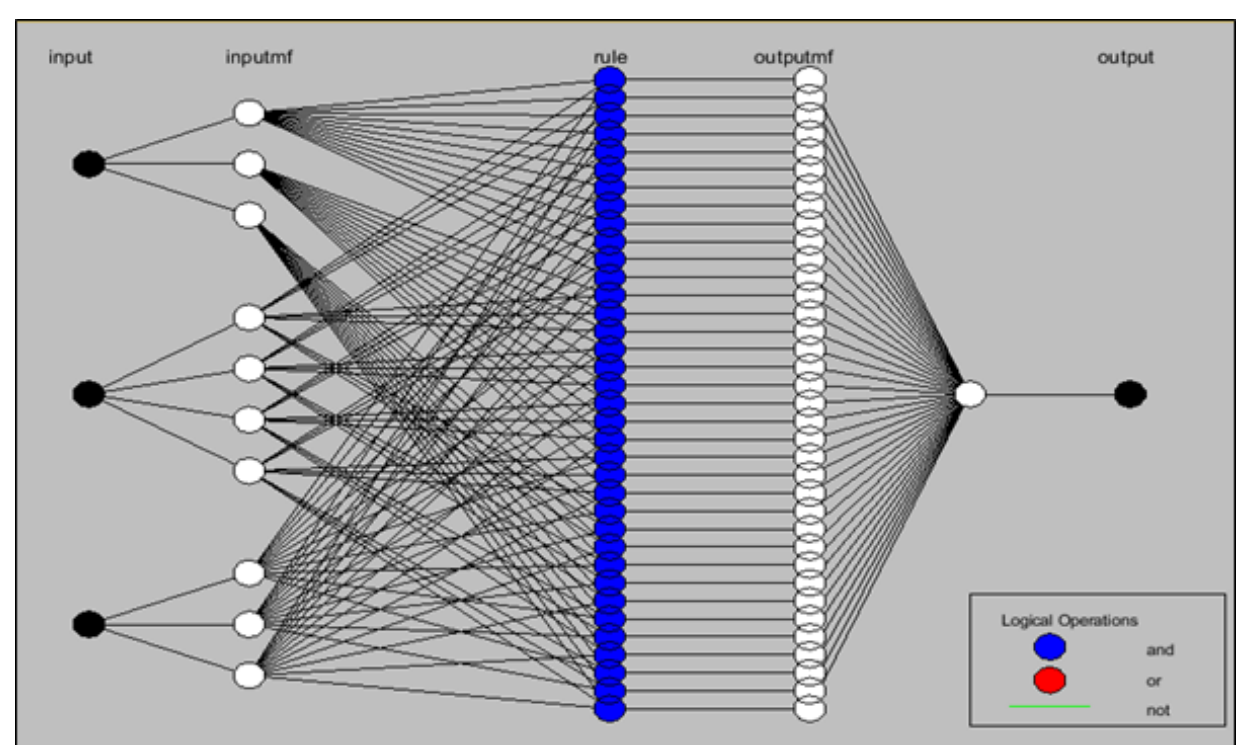

Figure 4. The designed ANFIS model structure (anfis:2 model)

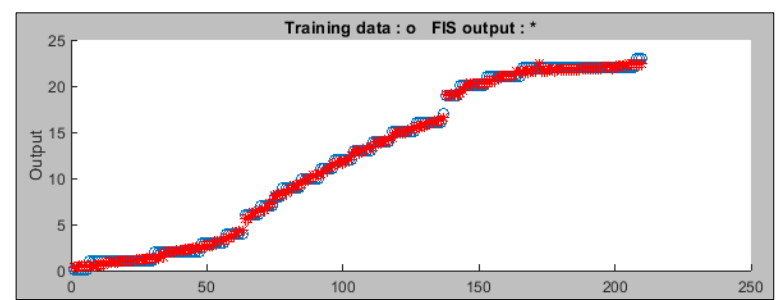

Figure 5. Actual and estimated data (training, anfis:2 model)

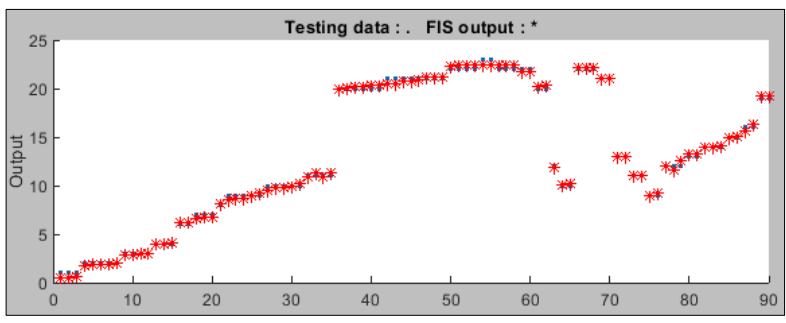

Figure 6. Actual and estimated data (testing, anfis:2 model)

anfis:1, anfis:2, anfis:3, anfis:4 and anfis:5 have been designed to obtain the more accurately estimations. Features of each designed ANFIS model are shown in Table 5.

The structure of anfis: 2 model with 98 nodes and 36 fuzzy rules, in which current, power and speed are used as input variables and torque as output variables is given in Fig. 4.

The actual and estimated data of anfis: 2 model for training and testing performances are given in Fig. 5 and Fig. 6, respectively.

A total of 36 rules were created in the anfis:2 model. $30 / 36$ of these created rules are shown in Fig. 7.

\subsection{Evaluation process}

Four distinct statistical evaluation methods were used to evaluate the each ANFIS model success. The estimation errors of these ANFIS models were calculated with $\mathrm{R}^{2}$, MAPE, MSE, RMSE metrics. Evaluation metrics are given in Table 6. 


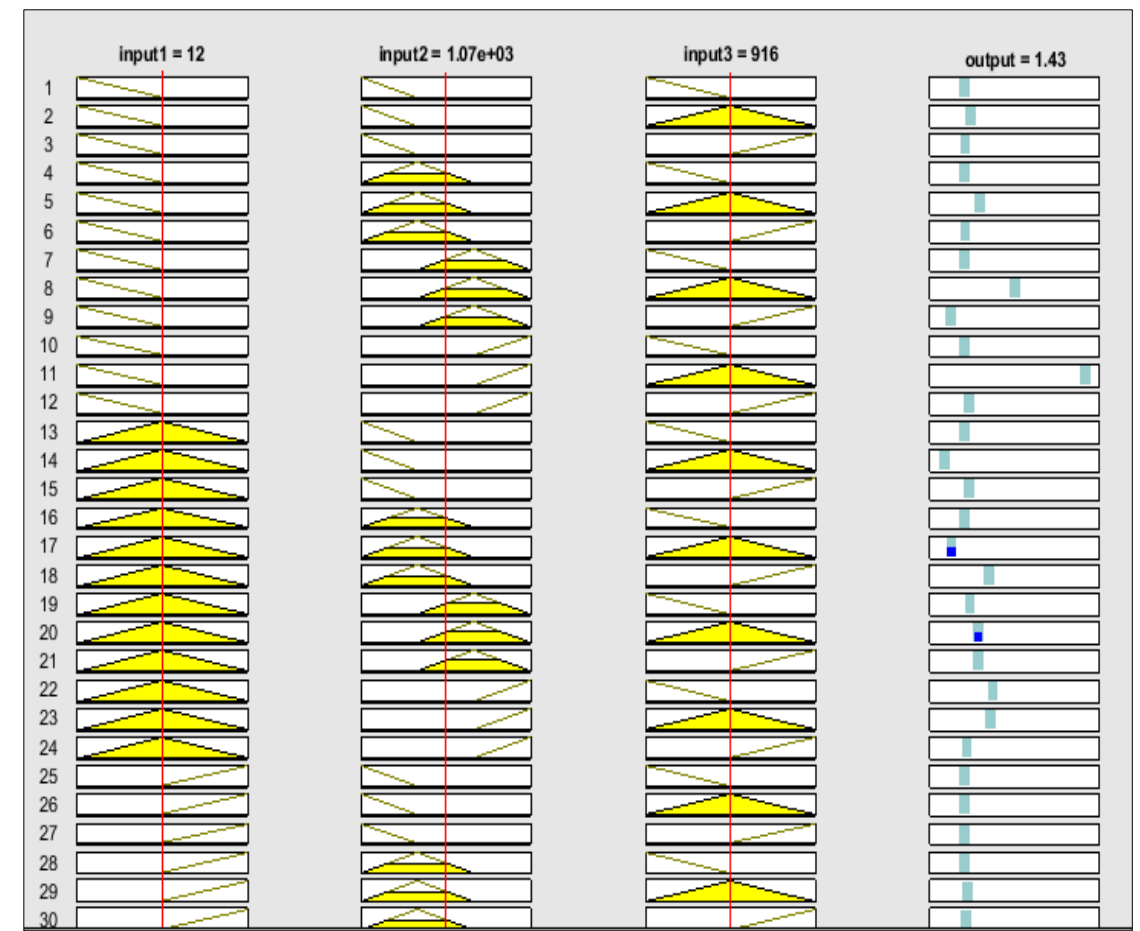

Figure 7. 30/36 of ANFIS rules (anfis:2 model)

Table 6. Evaluation metrics

\begin{tabular}{cccc}
\hline parameter & definition & description & equ. \\
\hline $\mathrm{R}^{2}$ & $R^{2}=1-\left(\frac{\sum_{i=1}^{n}\left(P^{*}-P\right)^{2}}{\sum_{i=1}^{n} P_{i}^{* 2}}\right)$ & $\begin{array}{c}\text { coefficient of } \\
\text { determination } \\
\text { mean absolute }\end{array}$ \\
MAPE & $\mathrm{MAPE}=\frac{1}{n} \sum_{i=1}^{n}\left|\frac{P^{*}-P}{P^{*}}\right| 100$ & $\begin{array}{c}\text { percentage error } \\
\text { mean square error } \\
\text { MSE }\end{array}$ & $\mathrm{MSE}=\frac{1}{n} \sum_{i=1}^{n}\left(P^{*}-P\right)^{2}$ \\
$\mathrm{RMSE}$ & $\mathrm{RMSE}=\sqrt{\frac{1}{n} \sum_{i=1}^{n}\left(P^{*}-P\right)^{2}}$ & $\begin{array}{c}\text { root mean square } \\
\text { error }\end{array}$ & (10) \\
\hline
\end{tabular}

Table 7. Estimation error results of designed ANFIS models

\begin{tabular}{lllllllll}
\hline \multirow{2}{*}{ models } & \multicolumn{2}{l}{ data set (training) } & \multicolumn{7}{c}{ data set (testing) } \\
\cline { 2 - 9 } & $\mathbf{R}^{\mathbf{2}}$ & MAPE & MSE & RMSE & $\mathbf{R}^{\mathbf{2}}$ & MAPE & MSE & RMSE \\
\hline anfis: 1 & 0,99980 & 2,024 & 0,017 & 0,309 & 0,99981 & 1,190 & 0,010 & 0,272 \\
anfis: 2 & 0,99978 & 2,324 & 0,018 & 0,307 & 0,99977 & $\mathbf{1 , 1 1 2}$ & 0,012 & 0,273 \\
anfis: 3 & 0,99972 & 2,466 & 0,022 & 0,300 & 0,99967 & 1,256 & 0,017 & 0,274 \\
anfis: 4 & 0,99978 & 2,498 & 0,019 & 0,305 & 0,99978 & 1,247 & 0,012 & 0,267 \\
anfis: 5 & 0,99958 & 3,486 & 0,032 & 0,281 & 0,99950 & 1,865 & 0,026 & 0,276 \\
\hline
\end{tabular}

where $P^{*}$ is the actual value and $P$ is the estimated value defined by equ. (7-10) [7, 11, 30]. anfis: 2 model's scattering diagram of measured and estimated torque values of training process and testing process are given Fig. 8. and Fig. 9, respectively.

Comparison of the torque estimation of designed anfis:1, anfis:2, anfis:3, anfis:4 and anfis: 5 models is given in Fig. 10.

The data used in this study, 210 data were classified as training data and 90 data as testing data, and a total of 300 data were used. According to MAPE error results for testing data sets, the anfis: 2 model has achieved the best value with 1,112 , and, the anfis:5 model has reached to worst value with 1,865 . Estimation error results of designed ANFIS models for both data sets are given in Table 7 .

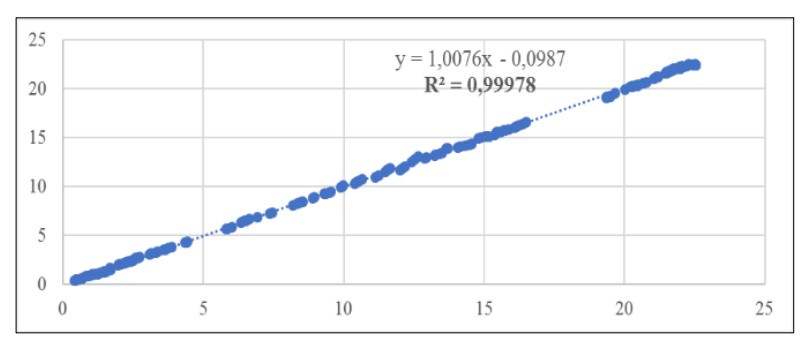

Figure 8. Scattering diagram of measured and estimated torque values of training process (anfis: 2 model) 


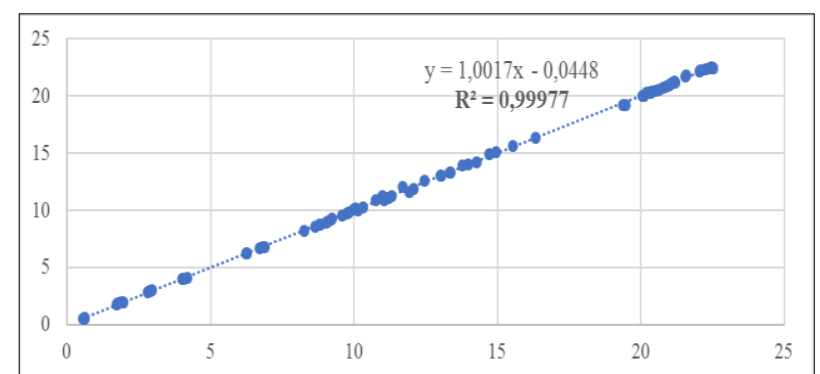

Figure 9. Scattering diagram of measured and estimated torque values of testing process (anfis:2 model)

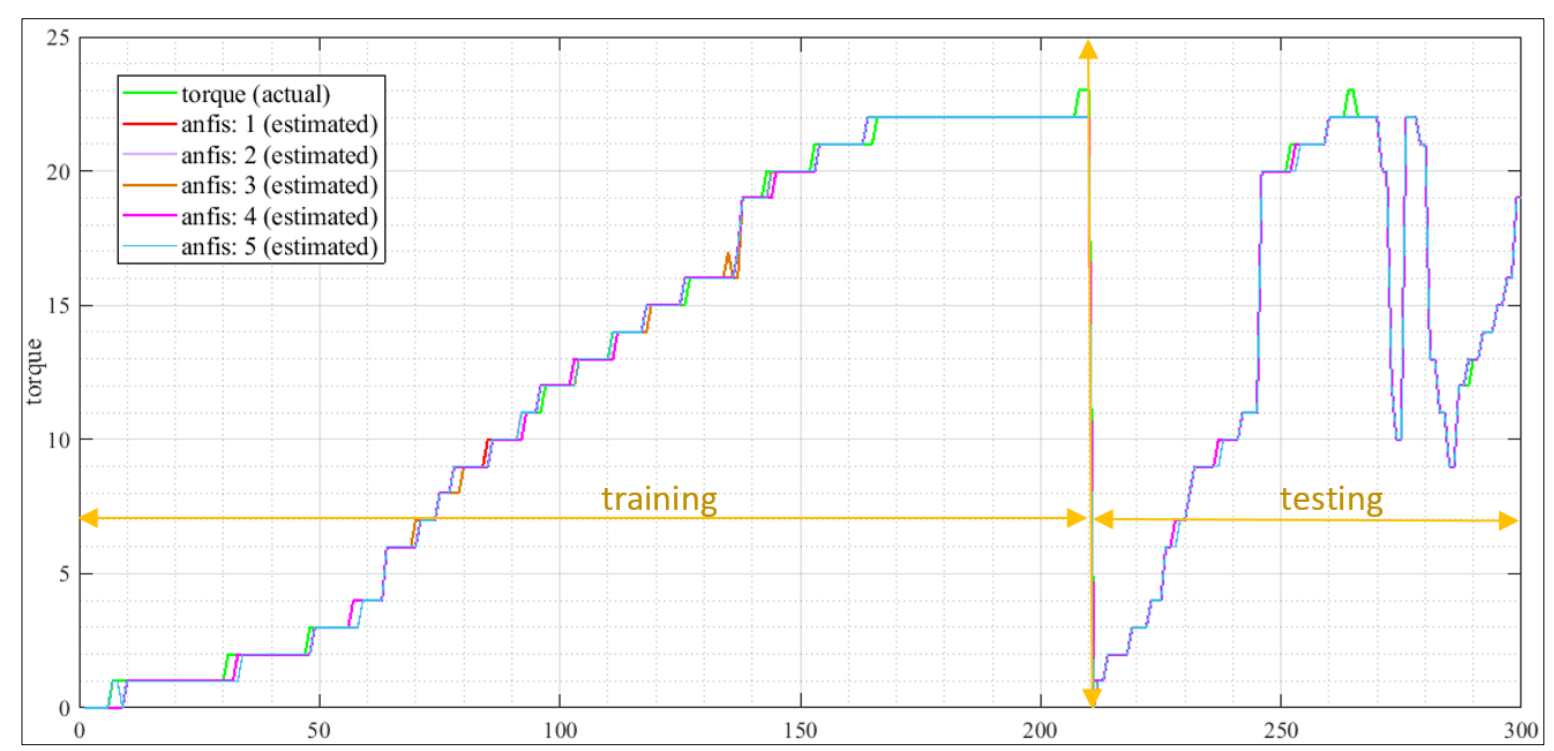

Figure 10. Comparison of the torque estimation of designed ANFIS models

\section{Conclusion}

In this study, the torque estimating studies of the EV motor were carried using ANFIS models. Used real-time data were obtained from ORPMBLDC motor, which was designed to be used in EV of Kahramanmaraş Sütçü İmam University, named Kurtuluş. According to the whole process of this study;

- Five distinct ANFIS models named anfis:1, anfis:2, anfis:3, anfis:4 and anfis:5 have been designed for reaching accurately estimations (given in Table 5).

- In all models, while the current, the power and the motor speed were determined as inputs variables, the torque were determined as an output variable (shown in Fig. 3).

- A total of 300 experimental data were used, including 210 data were determined for the training process and the remaining 90 data for the testing process.

- $\quad$ Four distinctive statistical metrics, $\mathrm{R}^{2}$, MAPE, MSE and RMSE, were used to observe the estimation performances.

- When the MAPE of testing results of five distinct ANFIS models were examined, it has seen that the anfis: 1 , anfis: 2 , anfis: 3 , anfis: 4 and anfis: 5 models were 1,190, 1,112, 1,256, 1,247 and 1,865, respectively (given in Table 7).

- It has seen that the best effective model was anfis: 2 with 98 nodes and 36 fuzzy rules, and, the worst model was anfis: 5 with 286 nodes and 125 fuzzy rules.

- For obtaining more accurately estimations studies with lower error values, the metaheuristic-based hybrid ANFIS models such as ANFIS-Particle Swarm Optimization (PSO), may also be studied for future estimation studies.

\section{Acknowledgement:}

This study was funded by Scientific Research Projects Coordination Unit of Kahramanmaraş Sütçü İmam University with 2020/4 - 16 M project number. And, thanks to Aegean Dynamics Corp. for assistance of the ORPMBLDC motor production process.

\section{References}

1. A. Kerem, "Elektrikli araç teknolojisinin gelişimi ve gelecek beklentileri", Mehmet Akif Ersoy Üniversitesi Fen Bilimleri Enstitüsü 
Dergisi, 5(1), 1-13, 2014.

2. R. Miceli, F. Viola, "Designing a sustainable university recharge area for electric vehicles: technical and economic analysis", Energies, 10, 1064, 2017.

3. A. Kerem, H. Gürbak, "Elektrikli araçlar için hızlı şarj istasyonu teknolojileri", Gazi Üniversitesi Fen Bilimleri Dergisi Part C: Tasarım ve Teknoloji, 8(3), 644-661, 2020.

4. V. Sandeep, S. Shastri, "Analysis and design of PMBLDC motor for three wheeler electric vehicle application", $1^{\text {st }}$ International Conference on Sustainable Energy and Future Electric Transportation, E3S Web of Conferences 87, 01022, 1-7, 2019.

5. S. Kahourzade, A. Mahmoudi, N. Abdul Rahim, H.W. Ping, "Sizing equation and finite element analysis optimum design of axial-flux permanent- magnet motor for electric vehicle direct drive", IEEE International Power Engineering and Optimization Conference, June 2012, Melaka, Malaysia, 2012.

6. A. İ. Özkan, M. Ciniviz, F. Candan, "Estimating engine performance and emission values using ANFIS", International Journal of Automotive Engineering and Technologies, 4(1), 63-67, 2015.

7. H. Harandizadeh, M.M. Toufigh, V. Toufigh, "Application of improved ANFIS approaches to estimate bearing capacity of piles", Soft Computing, 23: 9537-9549, 2019.

8. M.O. Okwu, O.D. Samuel, D.R.E. Ewim, Z. Huan, "Estimation of biogas yields produced from combination of waste by implementing response surface methodology (RSM) and adaptive neuro-fuzzy inference system (ANFIS)", International Journal of Energy and Environmental Engineering, 2021.

9. L. Naderloo, R. Alimardani, M. Omid, F. Sarmadian, P. Javadikia, M.Y Torabi, F. Alimardani, "Application of ANFIS to predict crop yield based on different energy inputs", Measurement, 45, 1406-1413, 2012.

10. M., Mohandes, S. Rehman, S.M. Rahman, "Estimation of wind speed profile using adaptive neuro-fuzzy inference system (ANFIS)", Applied Energy, 88, 4024-4032, 2011.

11. B. Najafi, S.F. Ardabili, "Application of ANFIS, ANN, and logistic methods in estimating biogas production from spent mushroom compost (SMC)", Resources,
Conservation \& Recycling, 133, 169-178, 2018. 12. P.D. Sreekanth, P.D. Sreedevi, S. Ahmed, N. Geethanjali, "Comparison of FFNN and ANFIS models for estimating groundwater level", Environ Earth Sci, 62, 1301-1310, 2011. 13. M.A. Raharja, I.D.M.B.A. Darmawan, D.P.E. Nilakusumawati, I.W. Supriana, "Analysis of membership function in implementation of adaptive neuro fuzzy inference system (ANFIS) method for inflation prediction", Journal of Physics: Conference Series, 1722, 2021.

14. A. Toghroli, M. Mohammadhassani, M. Shariati, M. Suhatril, Z. Ibrahim, N.H.R. Sulong, "Prediction of shear capacity of channel shear connectors using the ANFIS model", Steel and Composite Structures, 17, 5, 2014.

15. A. Baghban, J. Sasanipour, A.M. Goodarzi, "Evolving ANFIS model to estimate sweet natural gas water content", Petroleum Science and Technology, 35(18), 1807-1813, 2017.

16. P. Abbasi, M. Mohammad, A. Baghban, G. Zargar, "Evolving ANFIS model to estimate density of bitumen-tetradecane mixtures". Petroleum Science and Technology, 35(2), 120126, 2017.

17. R. Daneshfar, A. Bemani, M. Hadipoor, M. Sharifpur, H.M. Ali, I. Mahariq, T. Abdeljawad, "Estimating the heat capacity of non-newtonian ionanofluid systems using ANN, ANFIS, and SGB tree algorithms", Appl. Sci.10, 6432, 2020.

18. V.H. Quej, J. Almorox, J.A. Arnaldo, L. Saito, "ANFIS, SVM and ANN soft-computing techniques to estimate daily global solar radiation in a warm sub-humid environment", Journal of Atmospheric and Solar-Terrestrial Physics 155, 62-70, 2017.

19. A. Baghban, "Application of the ANFIS strategy to estimate vaporization enthalpies of petroleum fractions and pure hydrocarbons", Petroleum Science and Technology, 34(15), 1359-1366, 2016.

20. C.H. Cai, D. Du, Z.Y. Liu, "Battery state-of-charge (SOC) estimation using adaptive neuro-fuzzy inference system (ANFIS)", The IEEE Intemational Conference on Fuzzy Systems, 1068-1073. May 2003, St Louis, MO, USA, 2003.

21. R. Razavi, A. Sabaghmoghadam, A. Bemani, A. Baghban, K. Chaue, E. Salwana, 
"Application of ANFIS and LSSVM strategies for estimating thermal conductivity enhancement of metal and metal oxide based nanofluids", Engineering Applications of Computational Fluid Mechanics, 13(1), 560578, 2019.

22. B. Najafi, S.F. Ardabili, S. Shamshirband, K. Chaue, T. Rabczuk, "Application of ANNs, ANFIS and RSM to estimating and optimizing the parameters that affect the yield and cost of biodiesel production", Engineering Applications of Computational Fluid Mechanics, 12(1), 611624, 2018.

23. D.J. Armaghani, P.G. Asteris, "A comparative study of ANN and ANFIS models for the prediction of cement-based mortar materials compressive strength", Neural Computing and Applications, 2020.

24. D.J. Armaghani, E. Momeni, S.V.A.N.K. Abad, M. Khandelwal, "Feasibility of ANFIS model for prediction of ground vibrations resulting from quarry blasting", Environ Earth Sci,74, 2845-2860, 2015.

25. S. Amirkhani, Sh. Nasirivatan, A.B. Kasaeian, A. Hajinezhad, "ANN and ANFIS models to predict the performance of solar chimney power plants", Renewable Energy, 83, 597-607, 2015.

26. B. Ahmadi-Nedushan, "Prediction of elastic modulus of normal and high strength concrete using ANFIS and optimal nonlinear regression models", Construction and Building Materials, 36, 665-673, 2012.

27. A. Moghaddamnia, R. Remesan, M.H. Kashani, M. Mohammadi, D. Han, J. Piri, "Comparison of LLR, MLP, Elman, NNARX and ANFIS Models-with a case study in solar radiation estimation", Journal of Atmospheric and Solar-Terrestrial Physics, 71, 975-982, 2009.

28. A.A.M. Ahmed, S.M.A Shah, "Application of adaptive neuro-fuzzy inference system (ANFIS) to estimate the biochemical oxygen demand (BOD) of Surma River", Journal of King Saud University-Engineering Sciences, 29, 237-243, 2017.

29. X. Zhuang, T. Yu, Z. Sun, K. Song, "Wear prediction of a mechanism with multiple joints based on ANFIS. Engineering Failure Analysis", 119 (104958), 1-15, 2021.

30. M.A.A. Al-qaness, H. Fan, A.A. Ewees,
D. Yousri, M.A. Elaziz, "Improved ANFIS model for forecasting Wuhan City air quality and analysis COVID-19 lockdown impacts on air quality", Environmental Research, 194(110607), 1-12, 2021.

31. M.A. Jirdehi, V.S. Tabar, "State estimation in electric power systems based on adaptive neuro-fuzzy system considering load uncertainty and false data", Iranian Journal of Electrical and Electronic Engineering, 03(1722), 1-10, 2021.

32. V. Nourani, H. Karimzadeh, A.H. Baghanam, "Forecasting $\mathrm{CO}$ pollutant concentration of Tabriz city air using artificial neural network and adaptive neuro-fuzzy inference system and its impact on sustainable development of urban", Environmental Earth Sciences 80:136, 2021.

33. Y.B. Adyapaka Apatya, A. Subiantoro, F. Yusivar, "Design and Prototyping of 3-Phase BLDC Motor", $15^{\text {th }}$ International Conference on Quality in Research (QiR): International Symposium on Electrical and Computer Engineering, July 2017, Nusa Dua, Indonesia, 2017.

34. N. Marian-Ştefan, P. Raluca-Cristina, V. Ion, N. Petre-Marian, S. Ionuţ-Dani, "Particular Aspects Concerning the Design of a Brushless DC Electric Motor Driving a Mini-Scooter", International Conference on Applied and Theoretical Electricity (ICATE), Oct. 2016, Craiova, Romania, 2016.

35. M. Rameli, Y.R. Hais, R.E.A. Kadir, "Design of self commutation BLDC motor with torque control strategy using fuzzy logic in hybrid electric vehicle (HEV)", International Seminar on Intelligent Technology and Its Application, Aug. 2017, Surabaya, Indonesia, 2017.

36. S.Ganesh, S. Sankar, N. Selvaganesan, "Design and analysis of BLDC motor for aerospace application using FEM", International Conference on Intelligent Computing,Instrumentation and Control Technologies (ICICICT), July 2017, Kannur, India, 2017. 